Global and Stochastic Analysis

Vol. 5 • No. 6 • Special Issue 2018

MUK PUBLICATIONS

\title{
SATISFACTION OF TOURISTS TO HOI AN ANCIENT TOWN, VIETNAM
}

\author{
HA NAM KHANH GIAO, DINH KIEM, LE THAI SON AND TRUONG QUOC DUNG
}

\begin{abstract}
This research uses structural equation modelling (SEM) to test the correlation between service quality of the tourism destination and the satisfaction of the tourists who have visited Hôi An ancient town. SERVQUAL scale (Parasuraman et al, 1988) was used correctedly. The research also uses the methods of Cronbach's Alpha, exploratory factor analysis (EFA), confirmatory factor analysis (CFA) and SEM. The result shows that the tourist satisfaction has been affected by 3 factors: (1) Responsiveness; (2) Reliability; and (3) Empathy which were ranked by the importance. The research also raises some suggestions to the management and the tourist businesses at HÙi An in order to enhance the satisfaction through enhancing the service quality.
\end{abstract}

\section{Overview of Hoi and Ancient Town}

Hoi An is one of the two cities of Quang Nam province, Hoi An Ancient Town, which is recognized by UNESCO as World Cultural Heritage. On December 4, 1999, UNESCO listed Hoi An Ancient Town as a World Cultural Heritage Site. Hoi An also preserves a well-preserved cultural heritage. The link between the tangible cultural heritage and the intangible cultural heritage is unique, a "living museum" that creates outstanding, global values. Some typical cultural heritages include Cau Pagoda, ancient houses of Phung Hung, Tan Ky, Quan Thang, Phuc Kien, China, Trieu Chau, Quynh Phu and Quang Dong. Such as Thanh Ha pottery, Moc Kim Bong, Yen Thanh Chau. As for intangible culture, Hoi An people are an integral part to create a cultural heritage Hoi An world. Hoi An people with honest nature, hospitality ... always leave a hard impression in the hearts of visitors when visiting here. In addition, Hoi An has a special culinary culture, a crystallization between the culinary culture of the elite, creating a gastronomic background with its own. This particular feature is the use of local produce in these meals, creating unique specialties such as Cao Lau, Pho, cake rice, mash corn tea, noodles; Verses of singing, drumming, folklore festivals; Intangible cultural activities bearing the local cultural identity have affirmed Hoi An's "own" trademark such as "Night of the Old Town", "Street with no sound", Road Festival city, lantern, garment.

According to statistics, visitors to Hoi An in the period from 2008 to 2016 reached an average growth rate of $6.60 \%$ per year, especially the growth rate of $21.66 \%$ in 2017. In 2017, the total number of visitors to Hoi An reached 3.22 million, of which international visitors were 1.78 million, domestic visitors were 1.44 million. Although the number of visitors to Hoi An increased, but the number of guests staying in Hoi An tend to keep unchanged of around 2.5 days. This can be

Key words: Hoi An ancient town, satisfaction, service quality, EFA, CFA, SEM 
seen in some of Hoi An tourism products and service quality is still not diversified, not to attract tourists to stay. Therefore, the study of the factors of service quality that affects visitor satisfaction is essential in the current period.

\section{Theoretical Basis and Research Model}

\subsection{Travel destinations}

Gatrell (1994) defined destinations as geographic regions that have attributes, features, attractions and services to attract potential users. In a strategic perspective, Buhalis (2000) argued that the destination is a mix of service products, providing an integrated experience for consumers. Page \& Connell (2006) defined a destination as a mixture of pre-packaged products, services, accessibility, attraction, facilities, activities and support services. As such, a destination must have a certain range of facilities and services to offer visitors. Consequently, today, many cities and destinations are continually maintaining and improving their facilities to maintain competitive advantage, thereby allowing the destination to continue to maintain its market position.

\subsection{Quality of service and customer satisfaction}

Service is the result of interactions between suppliers and customers, as well as by suppliers' activities to meet consumer demand (ISO 9004-2: 1991E). According to Christopher \& Jochen (2004), service is an economic activity that creates value and benefits the customer in a certain place and time by responding to the wishes of the receiver.

"Quality is the level of a set of inherent characteristics of a product, system, or process to meet the requirements of customers and stakeholders." When visitors travel, they must use the provider's travel products and services, the results of the service provided through the interaction between the provider and the visitor, as well as by the activities of the supplier to meet the needs of the consumer (ISO 9004-2: 1991E). To measure visitor satisfaction, the quality of service is measured, as in the consumption process, the quality of service is reflected in the interaction between suppliers and visitors (Svensson, 2002).

Many researchers agree with the generalization of Parasuraman et al (1985). "Quality of service is determined by the difference between customer expectations of service and their evaluation of the service they receive." One of the primary theories on service quality is the theory of distance analysis (Zeithaml et al., 1990), which argues that consumers are satisfied when they evaluate the quality of service they receive. equal or exceed their expectations. Giao \& Vu (2011) summarized simple customer satisfaction as a meeting point or area that overlaps between the ability of the business and the needs of the customer; or the level of a person's sense of state begins with comparing the results obtained from the product / service with his or her expectations. Many researchers conducted a measure of service quality and customer satisfaction with the SERVQUAL scale (Cronin \& Taylor, 1992) with 5 components, a 5 point likert scale: (1) Tangible; (2) Empathy; (3) Responsiveness; (4) Reliability và (5) Assurance. 


\subsection{Research methods}

Cronbach's alpha testing is used to eliminate the rubbish before conducting factor analysis. Variables with a Corrected item total correlation less than 0.3 will be rejected. A reliability scale is good as it varies in the range $[0.70-0.80]$. If Cronbach alpha $\geq 0.60$, that is an acceptable scale of reliability (Nunnally \& Bernstein 1994).

Exploratory Factor Analysis (EFA) is used to identify groups of criteria for assessing service quality at Hoi An tourism destinations. EFA is used to abbreviate a $\mathrm{k}$ set of observed variables into a set $\mathrm{F}(\mathrm{F}<\mathrm{k})$ of the more significant factors. The basis of this reduction is based on the linear relationship of the factors with the observed variables.

The Confirmatory Factor Analysis (CFA) allows us to test how well we measure the measure variables representing constructs. The CFA method is used to confirm the univariate, multivariate, convergent and discriminant values of the scale of service quality.

Structural equation modeling (SEM) is used to test the proposed model. The structural model specifies the relationship between latent variables (a concept measured on many observable variables).

\subsection{Research models}

The proposed model is based on the theoretical and practical premises of Hoi An and is shown in Figure 1. Hypotheses should be tested:

$\mathrm{H}_{1}$ : Assurance has a positive effect on tourist satisfaction

$\mathrm{H}_{2}$ : Reliability has positive effects on tourist satisfaction

$\mathrm{H}_{3}$ : Empathy has a positive effect on tourist satisfaction

$\mathrm{H}_{4}$ : Response has a positive effect on tourist satisfaction

$\mathrm{H}_{5}$ : Tangible media has a positive effect on tourist satisfaction

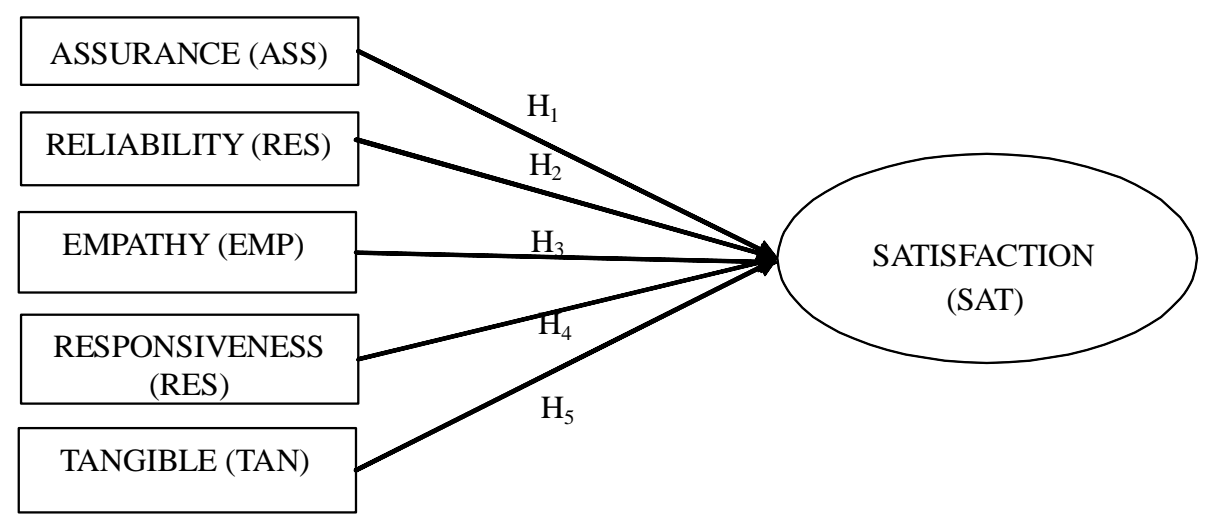

Figure 1: Proposed research model 


\section{Research Result}

\subsection{Qualitative research}

In the preliminary study, the author relied on a transformational scale from the SERVQUAL scale, and conducted a preliminary study with a focus group discussion to develop a preliminary scale and develop a questionnaire. From the preliminary questionnaire, the author interviewed 50 visitors, then consulted experts to adjust the wording for the questionnaire to understand and appropriate.

From the results of the preliminary study, after the adjustment, the official scale of research concepts was formed, preparing for quantitative research. Specific observations on measurements on Likert scale 5 points changed from $1=$ totally disagree to $5=$ completely agree.

\subsection{Survey}

The survey was conducted in May 2017, 300 questionnaires were distributed in Hoi An ancient town with convenient sampling method. The interviewees are domestic and foreign visitors to visit, resort ... here. 295 copies were used for the analysis, 5 were rejected because of incomplete information. The sample characteristics are presented in Table 1.

Table 1

Sample characteristics

\begin{tabular}{rlrr}
\hline \multicolumn{2}{c}{ Criteria } & Amount & Ratio \% \\
\hline \multirow{6}{*}{ Gender } & Male & 166 & 56.3 \\
& Female & 129 & 43.7 \\
& Total & 295 & 100.0 \\
& Sighective & 128 & 43.4 \\
& Resort & 60 & 20.3 \\
& Visiting relatives & 55 & 18.6 \\
& Business & 12 & 4.1 \\
& Others & 40 & 13.6 \\
& Total & 295 & $10 ., 0$ \\
\hline
\end{tabular}

\subsection{Scale measurement and measurement model}

Cronbach's Alpha results for Hoi An's service quality scales are shown in Table 2, item-total correlation is greater than 0.3. The scale meets the reliability, and is used in the EFA (Nunnally \& Burnstein, 1994).

Table 2

Results of Cronbach's Alpha measure of service quality in Hoi An

\begin{tabular}{llcc}
\hline & Scale & Number of Items & Reliability \\
\hline 1 & Assurance & 3 & 0.860 \\
2 & Reliability & 4 & 0.722 \\
3 & Responsiveness & 4 & 0.731 \\
4 & Tangible & 5 & 0.781 \\
5 & Empathy & 4 & 0.723 \\
6 & Satisfaction & 4 & 0.847 \\
\hline
\end{tabular}




\subsection{Factor analysis}

Exploratory Factor Analysis (EFA) results show that five factors were extracted at Eigen value 1.256 and the extraction variance was $59.351 \%$. Observed variables are grouped into factors as the initial assumption, with reliability in Table 2.

Table 3

Factor Matrix

\begin{tabular}{|c|c|c|c|c|c|}
\hline & & & ompone & & \\
\hline & 1 & 2 & 3 & 4 & 5 \\
\hline ASS1 & & & 0.865 & & \\
\hline ASS2 & & & 0.836 & & \\
\hline ASS3 & & & 0.756 & & \\
\hline REL1 & & & & 0.681 & \\
\hline REL2 & & & & 0.744 & \\
\hline REL3 & & & & 0.695 & \\
\hline REL4 & & & & 0.678 & \\
\hline RES1 & & 0.711 & & & \\
\hline RES2 & & 0.724 & & & \\
\hline RES3 & & 0.716 & & & \\
\hline RES4 & & 0.623 & & & \\
\hline TAN1 & 0.796 & & & & \\
\hline TAN2 & 0.786 & & & & \\
\hline TAN3 & 0.736 & & & & \\
\hline TAN4 & 0.603 & & & & \\
\hline TAN5 & 0.718 & & & & \\
\hline EMP1 & & & & & 0.652 \\
\hline EMP2 & & & & & 0.724 \\
\hline EMP3 & & & & & 0.748 \\
\hline EMP4 & & & & & 0.673 \\
\hline
\end{tabular}

\subsection{Confirmatory Factor Analysis (CFA)}

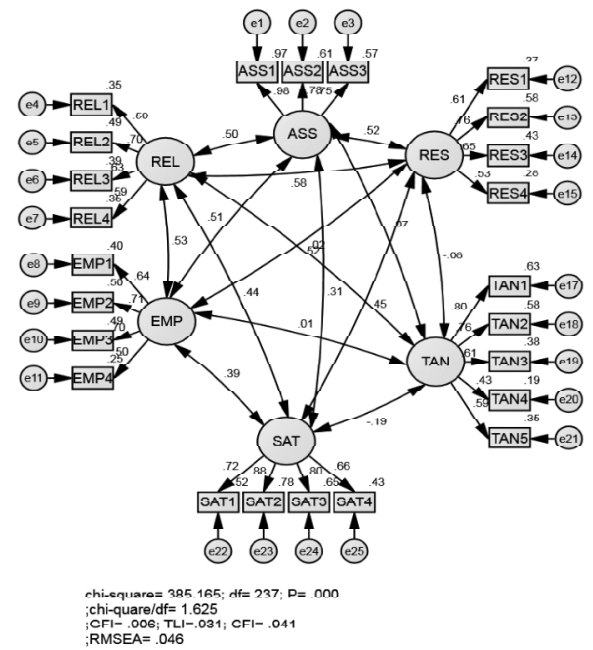

Figure 2a: CFA results of the Hoi An's service quality scale (standardized) 
* Measure the uniqueness and relevance of the model: CFA has Chi-squared results $=385.165$ with 237 degrees of freedom, $\mathrm{P}$-value $=0.000<5 \%$ statistically significant. $\mathrm{GFI}=0.906 ; \mathrm{TLI}=0.931 ; \mathrm{CFI}=0.941$ are $>0.9 ; \mathrm{CMIN} / \mathrm{df}=1.625$. The RMSEA $=0.046(<0.08)$ (Hair \& Works, 2010). According to Nunnally \& Burnstein (1994), with the four analytical indices mentioned above, the model of exploration is considered to be suitable for market data and to achieve uni-directionality.

* Convergence value measurement: The standardized weights of the scale are high $(>0.5)$, and the weights (unstandardized) are statistically significant bsecause P values are $<5 \%$ (Gerbing and Anderson, 1988). The measurement of the satisfaction of visitors to the ancient town of Hoi An has reached convergence. The results also show that the correlation coefficient of the TAN concept with other concepts has $\mathrm{P}$ value $>0.05$. Therefore, the authors abandon this concept and conduct a second $\mathrm{C} \overline{\mathrm{F}} \mathrm{A}$ analysis.

* Measuring the uniqueness and relevance of the second CFA model: Analysis confirms that CFA has Chi-squared results $=207,766$ with 142 degrees of freedom, $\mathrm{P}$-value $=0.000<5 \%$ statistically significant. GFI indices $=0.932 ; \mathrm{TLI}=0.961$; $\mathrm{CFI}=0.968$ are all $>0.9 ; \mathrm{CMIN} / \mathrm{df}=1.463$. The $\mathrm{RMSEA}=0.040(<0.08)$ (Gerbing and Anderson, 1988). The model is well fit to the data observed and is uni-directional.

* Reliability measurement: With the above calculated reliability of the groups after the EFA, the cronbach alpha values of the factor groups are found to range from 0.722 to 0.860 . The scale therefore achieves reliability.

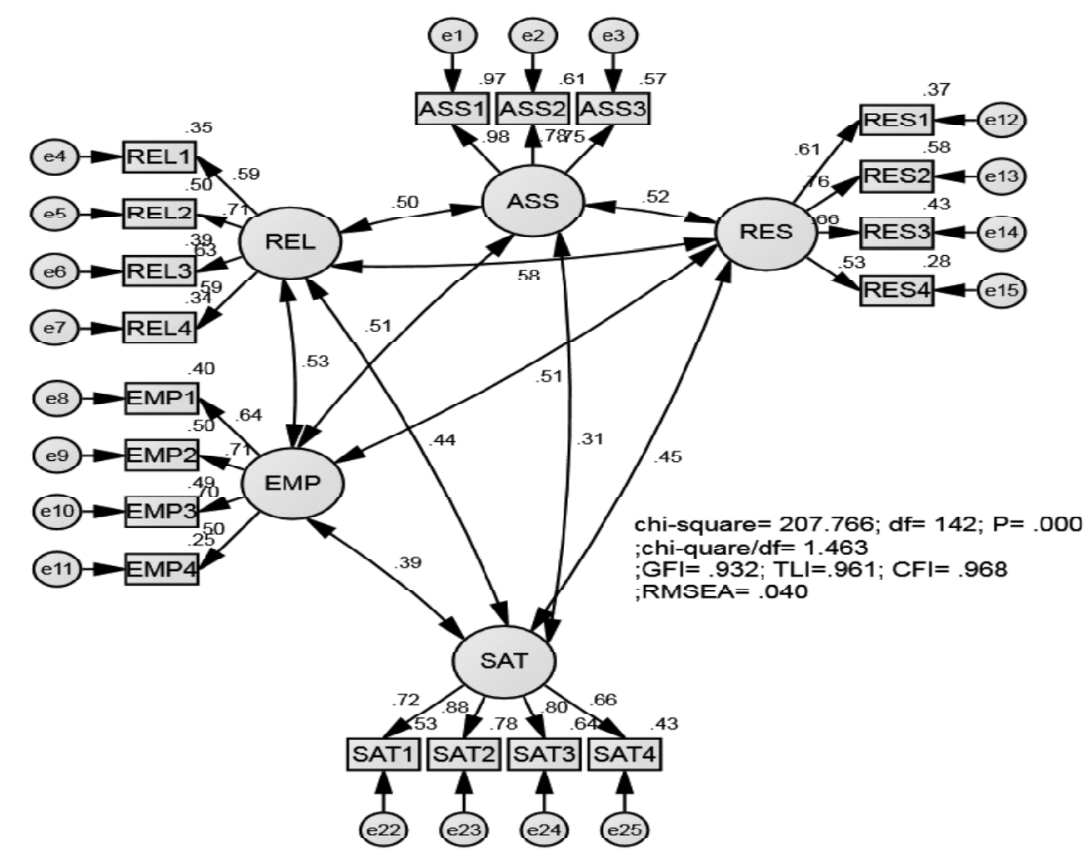

Figure 2b: Second CFA result of Hoi An ancient town's service quality (standardized) 
* Measure the convergence value at the second CFA: The standardized weights of the scale are high $(>0.5)$, and the weights (unstandardized) are statistically significant because $\mathrm{P}$ values are $<5 \%$ (Gerbing and Anderson, 1988). The measuring variables of the satisfaction of visitors to Hoi An ancient town are convergent. The analysis also showed that the correlation coefficient of each pair of $\mathrm{P}_{\text {_ value }}<0.05$ is different from the one in the $95 \%$ reliability, ensuring the convergence value.

* Distinctive value: The results of differential validation of variables in the critical model are shown in Table 4. All estimates correlated with the standard error (SE) for $\mathrm{p}$ were $<0.05$, so the correlation coefficient of each pair of concept differs from the one at $95 \%$ reliability. Consequently, concepts gain distinctive values.

Table 4

Result of distinctive values between factors in the model

\begin{tabular}{lllllll}
\hline & & Estimate & S.E. & C.R. & P & Label \\
\hline REL & $<->$ & ASS & 0.227 & 0.039 & 5.749 & $* * *$ \\
ASS & $<->$ & RES & 0.267 & 0.044 & 6.107 & $* * *$ \\
REL & $<->$ & EMP & 0.138 & 0.030 & 4.669 & $* * *$ \\
EMP & $<->$ & SAT & 0.118 & 0.027 & 4.301 & $* * *$ \\
RES & $<->$ & SAT & 0.184 & 0.037 & 5.034 & $* * *$ \\
EMP & $<->$ & RES & 0.151 & 0.032 & 4.717 & $* * *$ \\
REL & $<->$ & RES & 0.205 & 0.039 & 5.292 & $* * *$ \\
REL & $<->$ & SAT & 0.157 & 0.033 & 4.783 & $* * *$ \\
EMP & $<->$ & ASS & 0.192 & 0.035 & 5.423 & *** \\
ASS & $<->$ & SAT & 0.164 & 0.036 & 4.537 & $* * *$ \\
\hline
\end{tabular}

As a result, though the results of CFA measurement scale of tourism services in Hoi An, measuring scales include reliability, responsiveness, empathy and assurance which are well fit to the data observed, reaching unidirectional, ensuring convergence, reliability and distinctiveness.

\subsection{Structural equation modeling (SEM)}

\subsubsection{Structural equation modeling (SEM)}

The study uses the structural equation modeling (SEM) to assess the relevance of the research model and test relations in the model. The results of the SEM analysis with $\mathrm{df}=142$, Chi-square $=207.766$ and Chi-square $/ \mathrm{df}=1.463<2$, RMSEA $=$ 0.04 should confirm that the model is well fit to the data observed. 


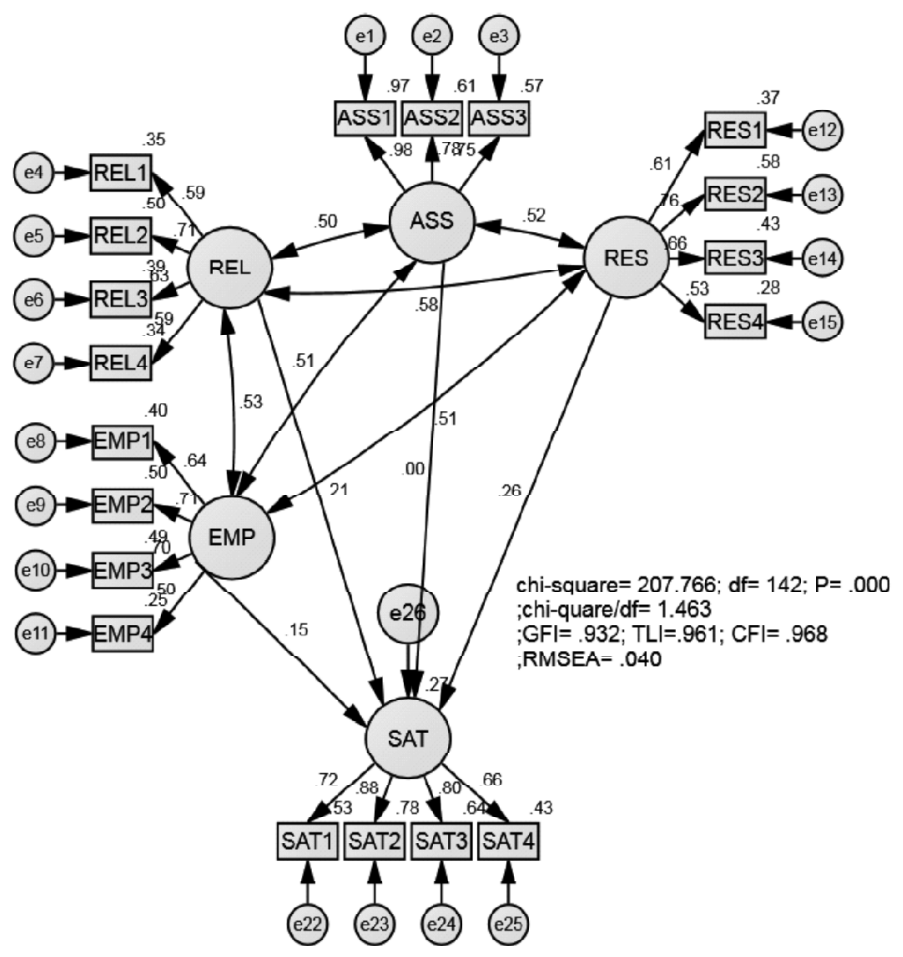

Figure 3: Test results of the SEM for service quality of Hoi An ancient town (standardized)

Table 5

Testing the relationship between concepts in the research model

\begin{tabular}{llccccc}
\hline & & Estimate & S.E. & C.R. & $P$ \\
\hline SAT & $<--$ & EMP & 0.210 & 0.128 & 1.646 & 0.100 \\
SAT & $<--$ & REL & 0.237 & 0.115 & 2.048 & 0.041 \\
SAT & $<--$ & ASS & 0.000 & 0.060 & -.005 & 0.996 \\
SAT & $<--$ & RES & 0.262 & 0.103 & 2.548 & 0.011 \\
\hline
\end{tabular}

From Table 5, the p value of Assurance concepts that affect Satisfaction is greater than 0.1. Thus, the relationship of concepts has not reached the theoretical expectation. In order to choose a more suitable model, relationships that are not statistically significant will be excluded from the model. Removing this group of factors from the model and running the SEM test again.

The final study model after eliminating relationships was not statistically significant for chi-square values $=142,044$ with $\mathrm{p}$ value $=0.002$, chi-square $/ \mathrm{df}=$ $1.453, \mathrm{GFI}=0.944 ; \mathrm{CFI}=0.969 ; \mathrm{TLI}=0.962$ and $\mathrm{RMSEA}=0.039$ indicates that the model matches the market data. 


\subsubsection{Accurate research hypotheses}

Table 6 shows that the standardized weightings are positive so it really affects the satisfaction of visitors to Hoi An ancient town. The response that had the greatest impact on satisfaction with the normalized weight was 0.26 . Next is the reliability with the standardized weight of 0.239 and finally the empirical with the standardized weight of 0.204 .

Table 6

Testing the relationship between concepts in the research model

\begin{tabular}{lcccccc}
\hline & & & Estimate & S.E. & C.R. & $P$ \\
\hline SAT & $<--$ & EMP & 0.204 & 0.121 & 1.685 & 0.092 \\
SAT & $<--$ & REL & 0.239 & 0.115 & 2.085 & 0.037 \\
SAT & $<--$ & RES & 0.260 & 0.099 & 2.635 & 0.008 \\
\hline
\end{tabular}

The unstandardized results of the parameters in Table 6 show that the relationships are statistically significant $(\mathrm{p}<0.1)$, that is, the hypotheses $\mathrm{H}_{2}, \mathrm{H}_{3}$, and $\mathrm{H}_{4}$ in the model are supported.

\subsubsection{Bootstrap verification}

The study uses the Bootstrap method with a repeated sample size of $\mathrm{N}=600$. The results of the estimation shown in Table 7 show that, although there is a deviation but a very small and stable value, in the research model is reliable.

Table 7

Bootstrap estimation results

\begin{tabular}{lcccccc}
\hline Relationship Estimates & SE & SE-SE & Mean & Bias & SE-Bias & CR \\
\hline SAT < - REL 0.207 & 0.119 & 0.003 & 0.202 & -0.005 & 0.005 & -1 \\
SAT < - EMP 0.152 & 0.115 & 0.003 & 0.146 & -0.005 & 0.005 & -1 \\
SAT < - RES 0.257 & 0.109 & 0.003 & 0.261 & 0.005 & 0.005 & 1 \\
\hline
\end{tabular}

According to the results of test hypothesis studies for the destination of Hoi An ancient town, hypothesis $\mathrm{H}_{2}$ which has the positive relationship between trust and satisfaction of tourists and hypothesis $\mathrm{H}_{3}$ which has the positive relationship between empathy and satisfaction are all accepted and hypothesis $\mathrm{H}_{4}$ has the positive relationship between responsiveness and satisfaction. These three pairs are of theoretical value.

From the theoretical model, the study identified the actual model as shown in Figure 4.

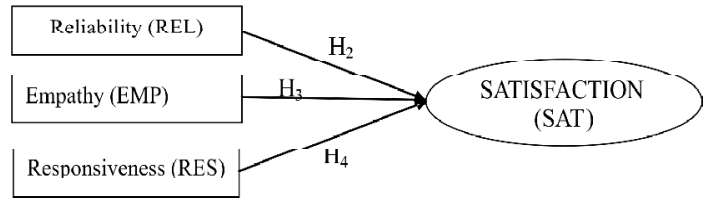

Figure 4: The model of the results of the satisfaction of tourists visiting Hoi An ancient town 


\section{Discussion}

The quality of service provided is one of the factors that affact customer satisfaction. A well-provisioned service will increase customer satisfaction and vice versa. Improved service quality will lead to improved customer service and customer satisfaction.

Research models may show practical applications that affect visitor satisfaction as follows:

First, responsiveness: this factor has the strongest impact on the model, and is highly dependent on the organizers providing products - services at attractions, resorts, fun points entertainment ... Diversified products - services which meet the expectations of visitors will contribute to satisfy tourists.

Second, reliability: demonstrates the ability to provide timely, appropriate services, ie, food and lodging providers; convenient communication system; Providing transportation between destinations, resorts. Visitors also pay attention to the security, safety when traveling, visiting the tourist sites, should management organizations, tourism business do well, this will build trust for visitors, they will have the peace of mind when traveling to Hoi An. In this study, reliability is the second most trusted component of the study after responsiveness.

Third, empathy: refers to the style of professional service, courtesy of the staff through attention to visitors, wholeheartedly to understand the needs of visitors to meet, create the sense of safety for visitors. Frequent staff training, especially professional style, courtesy, experience and deep understanding of the front line towards the needs of visitors will help visitors be more satisfied.

\section{Managerial Implication and Conclusion}

\subsection{Managerial implication}

Based on the results of the research and discussion mentioned above, the study could contribute some key recommendations to managers and tour operators in Hoi An. From interviews with visitors to Hoi An and from the test results of the model we have:

* The mean of the groups of factors is as follows:

Table 7

Mean Factors

\begin{tabular}{llcc}
\hline No. & Scales & Mean value & Deviation \\
\hline 1 & Responsiveness & 3.6907 & 0.78292 \\
2 & Empathy & 3.4424 & 0.70233 \\
3 & Reliability & 3.6907 & 0.78292 \\
\hline
\end{tabular}

From the above results, in general, tourists just assess the quality of services of Hoi An ancient town which is higher than the average but not much. This, in turn, helps tourism managers to better manage their accommodation, increase the number and quality of accommodations at affordable prices. In addition, there should be 
more transportation, communication and guidance to meet the needs of visitors when visiting here. Besides, around the sights, it is necessary to create more convenient services for visitors such as seats, public toilets, cashpoints, green space, landscape ...

Tourism managers and organizations also need to pay attention to investing more art performances bearing bold Hoi An culture to visitors, not only in Hoi An, but also in the specialized villages in Hoi An. This is a way for visitors to be in harmony with the people of Hoi An, visitors will be more satisfied because their needs are to see and participate in the activities. In addition, it is necessary to develop more specific products as souvenirs of Hoi An, these products only appear in Hoi An, having a unique souvenir gift will make visitors more satisfied.

The Empathy is underestimated, so it is necessary to increase the training of tourism staff at tourist sites of Hoi An, Cu Lao Cham, The provision of food, drink and other services such as safety, communication with customers ... should be given special attention. As this team will contribute to improving the quality of service, making visitors more satisfied when they come to Hoi An.

\section{Empathy}

Table 8

Average values of observed variables in the Empathy scale

\begin{tabular}{llc}
\hline No. & Contents & Mean \\
\hline 1 & $\mathrm{EMP}_{1}-$ the exhibition places of the ancient values of Hoi An ancient town & 3.3593 \\
2 & $\mathrm{EMP}_{2}-$ nightlife is more attractive & 3.5017 \\
3 & $\mathrm{EMP}_{3}-$ other services such as health care, relaxation & 3.4271 \\
4 & $\mathrm{EMP}_{4}-$ souvenirs, specialties & 3.4814 \\
\hline
\end{tabular}

The observed variables in the Empathy scale were not highly evaluated (mean, from 3.3 to 3.5). Increasing value of the galleries through ancient values in artifacts, myths, specialties, souvenirs bearing the characteristics of the ancient town will attract more tourists, the visit to Hoi An will leave a deep impression on visitors of an ancient town, the forms of trade and commerce that have the sense of the past will create more emotions that help visitors to satisfy and motivate visitors to return to find other interesting emotions in Hoi An old town when returning in the next trip.

Responsiveness

Table 9

Average values of observed variables in the Responsiveness scale

\begin{tabular}{llc}
\hline No. & Contents & Mean \\
\hline 1 & RES $_{1}-$ the hospitality of the people of the ancient town & 3.6542 \\
2 & $\mathrm{RES}_{2}-$ courteous, professional service & 3.7153 \\
3 & $\mathrm{RES}_{3}-$ the needs of visitors are met timely & 3.5525 \\
4 & $\mathrm{RES}_{4}-$ the peace of the locality at night & 3.8407 \\
\hline
\end{tabular}


The visitors' assessment of the Responsiveness is close to the needs of the travelers (mean of 3.5 to 3.8). To increase visitors' satisfaction with the service provider's responsiveness, regular training is required so that staff can know and quickly understand their needs and respond to them promptly. The training and training staff closely relate to the professional service style, but also indirectly affect the sense of hospitality when tourists travel in Hoi An. When the needs of visitors are met timely, visitors will feel more satisfied.

\section{Reliability}

Table 8

Average values of observed variables in the Reliability scale

\begin{tabular}{llc}
\hline No. & Contents & Mean \\
\hline 1 & REL $_{1-}$ number of rooms & 3.5966 \\
2 & REL $_{2-}$ cleanliness and comfort of the room & 3.5525 \\
3 & REL $_{3-}$ the demand for diverse cuisine of visitors & 3.4847 \\
4 & REL $_{4-}$ the suitability between room quality and room price & 3.4712 \\
\hline
\end{tabular}

The visitors' assessment for Reliability is not high with the visitors' needs for trust (the mean of about 3.5). To increase the visitor's satisfaction about the reliability of the tourism businesses, the price should be adjusted to suit the quality of the room, which means that for different types of rooms, the price should be the most appropriate for the room type. As the same time, enhancing other facilities, ensuring the cleanliness of guests' rest, leisure, entertainment will help to improve the satisfaction.

\subsection{Conclusion}

This research has identified the factors that affect the satisfaction of tourists to Hoi An as follows: The most influential one is Responsiveness, followed by Reliability and, finally, Empathy.

Based on the results of the study, the SEM model shows visitors' perceptions about each element of the components that affect the satisfaction of the visitors. It has suggested some ideas for managers and tourism business organizations to improve the quality of services to maximize the satisfaction of visitors. When the satisfaction of tourists is large, their ability to return to Hoi An ancient town is large, Hoi An ancient town brand is increasingly popular not only in the country but also internationally which contributes to developing tourism activities of the city. Finally, research has contributed to the addition of an experiment of quality service to a tourist destination, typically Hoi An ancient town in the present context.

Research has made a number of contributions in understanding the factors that affect the satisfaction of travelers when traveling to Hoi An ancient town. However, the research still has some limitations as the number of samples studied here is rather modest; The convenient method of sample sampling was not high. Future studies will increase the level of representation, increase the sample size and 
expand the scope of the survey to other tourist sites in Hoi An ancient town and contribute to the completion of this study.

\section{References}

1. Anderson, J., Gerbing, W., (1988). Structural equation modelling in practice: A review and recommended two stage approach. Psychological Bulletin, 27(1), 5-24.

2. Buhalis, D., (2000). Marketing the competitive destination of the future. Tourism Management, 21 (1): $97-116$

3. Cronin J J. \& Taylor S.A., (1994), "SERVPERF versus SERVQUAL: Reconciling performance Based and Perceptions-minus-expectations measurement of service quality", Journal of Marketing, 58 (January): 125-131.

4. Christopher, Lovelock \& Jochen, Wirtz, (2004), Services Marketing - People - Technology Strategy, Fifth Edition, Prentice Hall.

5. Gartrell, R.B., 1994. Destination Marketing for Convention and Visitor Bureaus. 2nd ed. Dubuque: Kendall/Hunt Publishing Co.

6. Giao, H.N.K. - Vu, N.T., (2011). Customers Satisfaction on the Service Quality of Vinatexmart. Economic Development Review, 253: 9-16.

7. Nunnally J. \& I. H. Bernstein (1994), Pschychometric Theory, 3rd ed., McGraw-Hill, New York.

8. Page, Stephen J. and Connell, Joanne, (2006). Tourism: a modern synthesis, 2nd ed. London: Thomson Learning.

9. Parasuraman, A., Zeithamlm, V.A. \& Berry, L.L (1985), "A conceptual model of service quality and its implications for future research", Journal of Marketing, 49(fall): 41-50.

10. Svensson, G. (2002), "A triadic network approach to service quality", Journal of services Marketing, 16(2): 158-179.

11. Zeithaml, V.A., Parasuraman, A. and Berry, L.L. (1990) Delivering Quality Service, Balancing Customer Perceptions and Expectations. Free Press, New York.

Ha Nam Khanh Giao, Associate Professor Doctor, Director of Institute of Applied Economics, University of Finance and Marketing, Vietnam

Dinh Kiem, PhD Visiting Lecturer of University of Finance and Marketing, Vietnam

Le Thai Son \& Truong Quoc Dung: PhD Candidate Visiting Lecturer of University of Finance and Marketing, Vietnam 